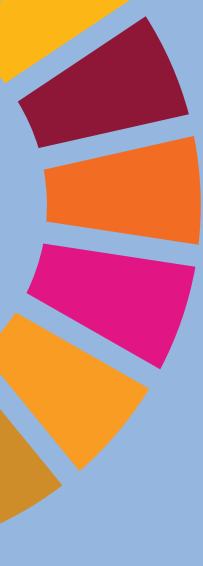

\title{
ETHICAL AND SUSTAINABLE FUTURE OF WORK
}

\section{UN FUTURO DEL TRABANO ÉTICO Y SOSTENIBLE}

\author{
David Pastor-Escuredo \\ Universidad Politécnica de Madrid \\ david.pastor@upm.es (Corresponding author) \\ Gianni Giacomelli \\ MIT Center for Collective Intelligence, Massachusetts \\ Institute of Technology \\ Julio Lumbreras \\ Universidad Politécnica de Madrid \\ Juan Garbajosa \\ Universidad Politécnica de Madrid
}

\section{ABSTRACT:}

Future work in the digital work requires ethical frameworks and Collective Intelligence to develop systems where humans and machines collaborate to come up with solutions promoting the Sustainable Development Goals. Many of the risk for future jobs can be mitigated if digitalization is driven from the lens of humancentered digital technology. However, this requires urgent changes in many processes and trends.

Keywords: Future of work, Artificial Intelligence, Digitalization, Collective Intelligence, Superminds, Sustainable Development Goals, Ethical work.

\section{RESUMEN}

El futuro del trabajo en la digitalización requiere tener marcos éticos y de Inteligencia Colectiva para desarrollar sistemas donde las máquinas y las personas colaboren para crear soluciones que permitan avanzar hacia los Objetivos de Desarrollo Sostenible. Gran parte de los riesgos para el futuro del trabajo se pueden mitigar si planteamos un desarrollo más humano de la digitalización, lo cual requiere cambiar con urgencia muchos procesos y tendencias. 
Palabras clave: Futuro del trabajo, Inteligencia Artificial, Digitalización, Inteligencia Colectiva, Supermentes, Objetivos de Desarrollo Sostenible, Trabajo ético.

David Pastor-Escuredo is a Ph.D. from UPM in Artificial Intelligence and Complex Systems. He was a pioneer collaborator of several United Nations agencies (UNGP, WFP, UNHCR) in Al and Data for Sustainable Development Goals. Currently he is a consultant for UNICEF. He has led digital innovation projects at itUPM managing partnerships with MIT research centers and labs. He is also a member of the Ethics and Digital Revolution group of itdUPM and "EI Dia Despues" cities community. He works in the Al for Healthcare within the program Catalyst Europe EIT Health-MIT and was awarded by EIT Health as best Catalyst project 2020.

\section{A NEW KIND OF INDUSTRIAL REVOLUTION}

Technology and automation in the industry are not new (Noble, 2017; Orlikowski, 1992) but it is certainly gaining new traction with the advances of robotics, Data and Artificial Intelligence (Acemoglu \& Restrepo, 2018; Madakam, Holmukhe, \& Jaiswal, 2019; Romero, Bernus, Noran, Stahre, \& Fast-Berglund, 2016). Each industrial revolution has implied a certain level of automation and shifts in jobs (Burnette, 2008), but the implication of new digital technologies and the so called Fourth Industrial Revolution (Schwab, 2017) are deeper and lead us to actually rethink the future of work and the role of humans (West, 2018; Willcocks $\&$ Lacity, 2016). Automation has resulted also in new types of jobs required for massive production and scalability. Some of these jobs have led to reduced creative skillsets. Digital automaton is certainly posing to replace operators with Al and robots at scale (Acemoglu \& Restrepo, 2018; West, 2018; Willcocks \& Lacity, 2016).

Digital Automation, implemented as the integration of technologies such as, but not only, Mobile Internet, Cloud computing, Internet of Things, Data, Al and Robotics, together with new processing schemas (i.e. edge computing (Satyanarayanan, 2017)) has become a labor disruption driver (OpendMind, 2020). Covid-19 surge has helped boost this disruption, defined as "a 'double-disruption' scenario for workers" (Forum, 2016, 2020). The scope of this disruption will not only include factories, but other physical spaces such as cities (Chen, Marvin, \& While, 2020; Tiddi, Bastianelli, Daga, d'Aquin, \& Motta, 2020) or farms (Asseng \& Asche, 2019).

The spatial awareness and psychomotor skills of humans are still quite beyond the state of the art of robots (Torricelli et al., 2016), both in rigid and soft robotics (Manti, Cacucciolo, \& Cianchetti, 2016). Nevertheless, the pace of new and better performing Machine Learning-based machines is increasing fast and we may be optimistic about robots taking over repetitive skills. The key issue will be the transition and reskilling of many workers a proper timing to avoid high rates of irreversible unemployment which will require specific policies. 


\section{SUSTAINABLE DEVELOPMENT GOALS AND FUTURE OF WORK}

There is an opportunity in digitalization to improve jobs quality and impact if digitalization is driven to achieve the Sustainable Development Goals (SDGs) such as gender equality, more decent work and sustainable industries and livelihoods, although risks exist (Griggs et al., 2013; Sachs, 2012; Vinuesa et al., 2020). Most part of these risks are associated with asymmetric transitions in several sectors putting many workers in vulnerable situations and increasing inequality. These risks are only magnified with the abrupt ongoing digitalized adaptation to COVID-19 (Forum, 2020).

Imagining how machines will reshape the future of work is not a new endeavor. In (Malone, 2004) it was proposed to envision future jobs from the lens of human-machines collaboration, interactions and deep organizational changes. Interactions and collaboration in systems imply thinking and understanding the collective level. Collective Intelligence emerges from groups when processes within groups result in more intelligence that the sum of individuals (Lévy \& Bononno, 1997; Malone, Laubacher, \& Dellarocas, 2009, 2010; Peach). The intersection of $\mathrm{Al}$ and $\mathrm{Cl}$ is a promising new paradigm to drive human-machine interactions for a better society including work (Mulgan, 2018). Looking at machines from a behavioral perspective (Rahwan et al., 2019) and interacting with humans in groups, we can design new tools, systems and algorithms that we can name as superminds (Malone, 2018). Here, we briefly discuss aspects of sustainable, inclusive, and ethical digitalization through $\mathrm{Al}$ and $\mathrm{Cl}$ that would enable growth, scientific progress and also better wellbeing.

Digitalization is an opportunity for healthier and more sustainable cities (SDG-11) and can help redefining jobs, for instance, surveillance, maintenance and promotion of public spaces (Filipponi et al., 2010). Data and $\mathrm{Al}$ will be an excellent basis for designing and managing all aspects related to urban design in depth, energy supplies (SDG-7) and urban policy making. Transportation and distribution related jobs will be also greatly shaped by digital technologies, autonomous vehicles and tools to analyze mobility flows and realtime demand. Commerce, Restaurants, Hospitality, and Travel and Tourism are already undergoing a digital transformation where the physical and digital worlds will converge into new virtually-enhanced spaces that will transform the relationship with customers (SDG-9). Risk assessments and response to natural disasters (Pastor-Escuredo, Torres, Martínez-Torres, \& Zufiria, 2020), epidemics (Martín-Calvo, Aleta, Pentland, Moreno, \& Moro, 2020) and crisis based on Data and Al are becoming already a reality that will change resilience and response mechanisms and the action of public servants and emergency bodies. Humancentered cities will imply providing more services to citizens, searching for their engagement and also become more resilient and sustainable, for instance through decarbonization (SDG-7, SDG-13).

Rural areas can greatly improve their conditions through digitalization, attracting more population and business if work in the fields becomes more technological, digitally connected and resilient. Factories and manufacturers could increase their productivity with a relief of excessive work schedules for their workers in important sectors such as nutrition and fashion. That process of digitalization and robotization of physical spaces implies interactions between different SDGs such as sustainable communities (SDG-11), climate change (SDG-13), life in land (SDG-15), responsible consumption (SDG-12), hunger (SDG-2), poverty (SDG1) and better work (SDG-8). Digitalization can really change the landscape of livelihoods in any region of the world producing deep changes in jobs demand and the need of skills, provided the economic sustainability and also the cultural acceptance. Furthermore, the environmental impact of digitalization will be an important matter as part of a sustainable and ethical future of work and livelihoods (SDG-15). More technological and scientific advances and a better understanding how machines and humans can interact in physical spaces are needed. 
Although there are promising advances in robotics and Machine Learning algorithms specially based on Reinforcement Learning (Polydoros \& Nalpantidis, 2017). It is remarkable that very dull tasks that humans find easy are complex for Al. Until machines can perform fully automated tasks with safety and security requirements, human-in-the-loop solutions will be likely required. This suggests that the physical interaction of humans with things and the environment is a very unique characteristic of humans (and animals). Physical interaction and performance embody many mechanisms through our extremities, senses and nervous system. This fact suggests that future jobs should better exploit these unique skills and capabilities. This is not the trend as works still tend to be more centered on digital interfaces with machines that are available in fixed spaces. Enhancing physical experience and interactions in non-usual places is a way forwards for humans as species and to leverage their innate skills. Different digital interfaces that allow humans to work in different types of physical spaces can have a great impact in the use of cities and green spaces (SDG11), physical and mental health and well-being (SDG-3) and life on land (SDG-15). In that sense, Al, Virtual Reality (Burdea \& Coiffet, 2003; Tepper et al., 2017) and Internet of Things (Li, Da Xu, \& Zhao, 2018; Ray, 2018) are the grounding technologies to develop "phygital" spaces where humans can carry out different types of socio-economic and commercial activity in deeper connection with the environment.

Digitalization should lead humans to interact better and more with the ecosystem. Al has shown promising applications for predictive analytics about environmental conditions and measuring the impact of different types of anomalies in livelihoods (Pastor-Escuredo et al., 2020; Zufiria et al., 2018). Data and Al can help communities to increase the efficiency and adaption of their livelihoods to climate change (SDG-13) and be more resilient to crisis and natural disasters (SDG-11) or situations of conflict (SDG-16). In that sense, migration and mobility related to labor markets which is a very significant social phenomenon in many countries around the globe could be better monitored. Labor-related migrations are a source of problems related to epidemics (SDG-3), conflicts and segregation (SDG-16), poverty and hunger (SDG-1 and SDG-2) and also vulnerability and inequalities (SDG-10), specially for women that in many cases have to carry on ensuring the safety and survival of households (SDG-5).

\section{COLLECTIVE INTELLIGENCE AS A DESIGN PRINCIPLE}

Collective Intelligence should ground digitalization to better interact with the ecosystem, approached from a systemic perspective. The specific tools that communities of farmers, manufacturers and suppliers require are yet to be designed helping to improve individual decision making (i.e. taking decision about hiring manpower or migrating to urban areas por job searching) but also better decisions that take into account the complexities of livelihoods (Scoones, 2009). This type of collective decision making may include deciding crops, sowing and harvesting strategies, community-level mobility and coping strategies or the creation of new partnerships and stakeholder engagement to leverage resources or financial stimulation.

A more interconnected management of industries and value chains requires better monitoring. Digital technologies can enable remote tasks minimizing risk and relieving from tiresome activities. Computer vision, Internet of Things and drones are technologies that can be leveraged for security and monitoring replacing humans in risky jobs. There are opportunities for better future of work in the sense that monitoring factories and work-spaces can help ensure that labor rights are enforced and promoted according to international regulations. Blockchain is a digital technology that enables digital traceability of financial and operational activities along the value chain that will facilitate measuring the impact of industries in social, financial, economic and environmental dimensions which will transform how organizations make decisions. Digital traceability has a great potential to ensure sustainable practices along the value chain (SDG-8 and SDG- 
9) and also facilitating trustful ecosystems between partners (SDG-17) helping improve evaluation within consortiums and commercial relationships. It is necessary to highlight that there is an intrinsic ethical risk of staff freedom and morale regarding all types of monitoring and surveillance. Monitoring systems have to be designed from ethical perspective and human-centered to ensure that they are respectful with privacy and promote that workers become more engaged and motivated.

Now looking at the individual and organization levels, cognitive skills will evolve in the digital era. The tasks that have traditionally performed through body-level physical interfaces are being adapted to virtual interfaces mainly driven by a deeper and more intensive vision and hand-driven manipulation. The capacity to ingest visual content at high speed is one of the main characteristics of digital citizens. These skills, as a complement of body-driven action can also be a source of imagination, integrative thinking and embodied visual analytics. Such skills are specially relevant for new systems of decision making that require the integration of high-dimensional spaces accounting for many variables and indicators. Holistic systems based on real-time data and IA algorithms and tools will likely become part of high-level management. The interaction and the navigation through high-dimensionality and complex data will be critical and will require new skills beyond data analytics. We can expect visual data analytics and sense making to be a more specialized task to interpret data and make decisions. Hybrid scientific and management teams are already becoming a reality in data-driven business and in emergencies teams managing complex processes such as epidemics.

However, complexity will increase not only because of internal information flows, but also because of their connectedness with the ecosystem. Decision making tools will be required across the skeleton of corporations to allow fast response to external stimuli, build up adaptation and resilience mechanisms and generate Collective Intelligence. Sensing and signaling mechanisms between parts of the organizations will be critical and those should be based on Al to avoid introducing a larger burden on managers and workers. In that sense, we can learn from biological systems that basic sensing mechanisms between cells generate harmonized functioning and development of tissues. The tissue analogy works properly to model how companies should work as an alternative to tight hierarchies. As in biological processes, tissues are multi-scale (Pastor-Escuredo $\&$ del Alamo, 2020) which means that connectedness and signaling can go beyond the organization level and help connecting organizations across sectors. It will be relevant for long-term sustainability and deep transformations to understand how organizations can communicate and collaborate at different levels using digital technologies (SDG-17). Al, Data and Blockchain will help measure better the transactions and valueinteractions between organizations promoting transparency, collaboration and accountability.

Although human resources have already undergone a significant level of digitalization, profiling and matching algorithms of candidates and employees will keep growing, specially if private data is shared across social and professional networks. The risks in terms of privacy, discrimination and biases have been already warned, but Al, Data and digital tools are still a great opportunity to build human-based tissues within organizations to increase creativity, variety and motivation. In the last years, we have witnessed the creation of networks of experts and stewards to promote collaboration and data collaboratives (Verhulst, Zahuranec, Young, \& Winowatan, 2020). These are good models of how new capacities and roles will be created within organizations to harness the potential of digital-based collaboration and new connections in value chains.

In the same way we start monitoring devices and physical systems through with the Internet of Things and other digital technologies, there is a potential risk in the instrumentalization of people and machines for the sake of efficiency and performance. Human empowering $\mathrm{Cl}$ is a proper framework to evaluate how digitalization should be developed to create and manage teams beyond the existing tools for collaboration 
and creation of intellectual or industrial assets (Malone, 2018; Malone et al., 2010). Behavioral science, psychology and augmented $\mathrm{Cl}$ are elements that have to be integrated to properly design the internal digitalization of teams and the creation of superminds. Co-creation is a critical element of team building and collaboration and can be greatly improved by integrating the ideas of teams with tools to search and check evidence and also nowcasting the needs and trends of the society using Big Data and Al. Thus, digitalization is an opportunity for democratized and shared ideas and projects that are also well connected with the realworld and are evidence-based. Besides, immersive virtual environments will change how remote work is done, allowing distant collaboration and work to be much more effective. Measuring impact of projects, teams and partnerships will be also critical at all scales. Impact assessment tools are yet to be developed beyond the current KPIs frameworks. Holistic frameworks that account for the dynamics and synergies of groups and the SDGs will help promoting more decent work and more sustainable organizations.

\section{ETHICAL IMPLICATIONS}

As discussed, it can be argued that $\mathrm{Al}$ and Data biases will be a great problem than a solution (Kusner \& Loftus, 2020). However, existing corporations are not free of biases. Cognitive biases are frequent as well as biased generated by personal interests and power relationships. Another role of Al that can shape the future of work is as a mediator and as a catalyzer to change power structures within corporations. Transparent and accountable algorithms are now driven many of customer-oriented decisions of many platforms that were natively digital or have gone digital in the recent years. We can expect algorithms to make decisions affecting internal organization and managing management. Decentralized Autonomous Organizations built on Blockchain and smart contracts are an example of new paradigms of algorithmic organization. This paradigm encompasses a clear risk that machines will eventually be the organizers and managers ruling humans for the sake of efficiency and efficacy. Hybrid human-machine systems designed from the lens of $\mathrm{Cl}$ can potentially be the solution to this wicked problem.

Eventually, the real ethical question and scientific challenge is if machines can help humans be more fair in their decisions, increase their awareness and knowledge to avoid biases, have a more holistic and comprehensive vision of needs for a sustainable society and self-regulate from self-interest (Laffont \& Martimort, 2009; Pastor-Escuredo \& Vinuesa, 2020).

Avoiding the risks for ethical and sustainable future world demands proactive actions from policies and financial instruments to specific research and collaboration-based ecosystems, as well as regulation capable to respond to the evolution of Al including risks and opportunities for SDGs and social well-being. Both the right design of Al-driven jobs and industry and the institutional role (policies, stimuli and regulation) will determine if Al really can lead to economic growth (Aghion, Antonin, \& Bunel, 2019) and be a driver for sustainable development. Al design has to be integrated with ethical and SDGs-driven frameworks to envision human-machine systems that empower workers and ease the transition to a more digitalized society where workers will need new skillsets. However, in most cases, trends of digitalization are leading to scenarios of vulnerability, rushed up by the COVID-19 pandemia. It is urgent to design and implement new systems and superminds that help build resilience and drive changes within organizations, sectors and livelihoods to open new spaces and opportunities for all type of workers.

Acknowledgements. Authors acknowledge the MIT/MISTI-Spain Seed Funds "Empowering Collective Intelligence With Artificial Intelligence To Enhance And Scale Sustainable Development (Sustainable Cities)" that partially support the preparation of this paper. 


\section{REFERENCES}

- Acemoglu, D., \& Restrepo, P. (2018). Artificial intelligence, automation and work (0898-2937). Retrieved from

- Aghion, P., Antonin, C., \& Bunel, S. (2019). Artificial Intelligence, Growth and Employment: The Role of Policy. Economie et Statistique, 510(1), 149-164.

- Asseng, S., \& Asche, F. (2019). Future farms without farmers. Science Robotics,[si], 8(27), 1-2.

- Burdea, G. C., \& Coiffet, P. (2003). Virtual reality technology: John Wiley \& Sons.

- Burnette, J. (2008). Gender, work and wages in industrial revolution Britain: Cambridge University Press.

- Chen, B., Marvin, S., \& While, A. (2020). Containing COVID-19 in China: Al and the robotic restructuring of future cities. Dialogues in Human Geography, 2043820620934267.

- Filipponi, L., Vitaletti, A., Landi, G., Memeo, V., Laura, G., \& Pucci, P. (2010). Smart city: An event driven architecture for monitoring public spaces with heterogeneous sensors. Paper presented at the 2010 Fourth International Conference on Sensor Technologies and Applications.

- Forum, W. E. (2016). The future of jobs: Employment, skills and workforce strategy for the fourth industrial revolution. Paper presented at the Global challenge insight report. Geneva: World Economic Forum.

- Forum, W. E. (2020). The future of jobs report 2020.

- Griggs, D., Stafford-Smith, M., Gaffney, O., Rockström, J., Öhman, M. C., Shyamsundar, P., . . Noble, I. (2013). Policy: Sustainable development goals for people and planet. nature, 495(7441), 305.

- Kusner, M. J., \& Loftus, J. R. (2020). The long road to fairer algorithms. In: Nature Publishing Group.

- Laffont, J.-J., \& Martimort, D. (2009). The theory of incentives: the principal-agent model: Princeton university press.

- Lévy, P., \& Bononno, R. (1997). Collective intelligence: Mankind's emerging world in cyberspace: Perseus books.

- Li, S., Da Xu, L., \& Zhao, S. (2018). 5G Internet of Things: A survey. Journal of Industrial Information Integration, 10, 1-9.

- Madakam, S., Holmukhe, R. M., \& Jaiswal, D. K. (2019). The future digital work force: Robotic process automation (RPA). JISTEM-Journal of Information Systems and Technology Management, 16.

- Malone, T. W. (2004). The future of work: Audio-Tech Business Book Summaries, Incorporated.

- Malone, T. W. (2018). How human-computer'Superminds' are redefining the future of work. MIT Sloan Management Review, 59(4), 34-41.

- Malone, T. W., Laubacher, R., \& Dellarocas, C. (2009). Harnessing crowds: Mapping the genome of collective intelligence.

- Malone, T. W., Laubacher, R., \& Dellarocas, C. (2010). The collective intelligence genome. MIT Sloan Management Review, 51(3), 21.

- Manti, M., Cacucciolo, V., \& Cianchetti, M. (2016). Stiffening in soft robotics: A review of the state of the art. IEEE Robotics \& Automation Magazine, 23(3), 93-106.

- Martín-Calvo, D., Aleta, A., Pentland, A., Moreno, Y., \& Moro, E. (2020). Effectiveness of social distancing strategies for protecting a community from a pandemic with a data driven contact network based on census and real-world mobility data. Retrieved from

- Mulgan, G. (2018). Artificial intelligence and collective intelligence: the emergence of a new field. Al \& SOCIETY, 33(4), 631-632. 
- Noble, D. (2017). Forces of production: A social history of industrial automation: Routledge.

- OpendMind, B. (2020). El trabajo en la era de los datos. Retrieved from https://www.bbvaopenmind.com/ libros/el-trabajo-en-la-era-de-los-datos/

- Orlikowski, W. J. (1992). The duality of technology: Rethinking the concept of technology in organizations. Organization science, 3(3), 398-427.

- Pastor-Escuredo, D., \& del Alamo, J. C. (2020). How computation is helping unravel the dynamics of morphogenesis. Frontiers in Physics, 8, 31.

- Pastor-Escuredo, D., Torres, Y., Martínez-Torres, M., \& Zufiria, P. J. (2020). Rapid Multi-Dimensional Impact Assessment of Floods. Sustainability, 12(10), 4246.

- Pastor-Escuredo, D., \& Vinuesa, R. (2020). Towards and Ethical Framework in the Complex Digital Era. arXiv preprint arXiv:2010.10028.

- Peach, K. Combining Crowds and Machines.

- Polydoros, A. S., \& Nalpantidis, L. (2017). Survey of model-based reinforcement learning: Applications on robotics. Journal of Intelligent \& Robotic Systems, 86(2), 153-173.

- Rahwan, I., Cebrian, M., Obradovich, N., Bongard, J., Bonnefon, J.-F., Breazeal, C., .. Jackson, M. O. (2019). Machine behaviour. nature, 568(7753), 477-486.

- Ray, P. P. (2018). A survey on Internet of Things architectures. Journal of King Saud University-Computer and Information Sciences, 30(3), 291-319.

- Romero, D., Bernus, P., Noran, O., Stahre, J., \& Fast-Berglund, Å. (2016). The operator 4.0: human cyberphysical systems \& adaptive automation towards human-automation symbiosis work systems. Paper presented at the IFIP international conference on advances in production management systems.

- Sachs, J. D. (2012). From millennium development goals to sustainable development goals. The Lancet, 379(9832), 2206-2211.

- Satyanarayanan, M. (2017). The emergence of edge computing. Computer, 50(1), 30-39.

- Schwab, K. (2017). The fourth industrial revolution: Currency.

- Scoones, I. (2009). Livelihoods perspectives and rural development. The journal of peasant studies, 36(1), 171-196.

- Tepper, O. M., Rudy, H. L., Lefkowitz, A., Weimer, K. A., Marks, S. M., Stern, C. S., \& Garfein, E. S. (2017). Mixed reality with HoloLens: where virtual reality meets augmented reality in the operating room. Plastic and reconstructive surgery, 140(5), 1066-1070.

- Tiddi, I., Bastianelli, E., Daga, E., d'Aquin, M., \& Motta, E. (2020). Robot-city interaction: Mapping the research landscape-a survey of the interactions between robots and modern cities. International Journal of Social Robotics, 12(2), 299-324.

- Torricelli, D., Gonzalez, J., Weckx, M., Jiménez-Fabián, R., Vanderborght, B., Sartori, M., ... Pons, J. L. (2016). Human-like compliant locomotion: state of the art of robotic implementations. Bioinspiration \& biomimetics, 11(5), 051002.

- Verhulst, S., Zahuranec, A., Young, A., \& Winowatan, M. (2020). Wanted: data stewards.(Re-) defining the roles and responsibilities of data stewards for an age of data collaboration. New York: The GovLab. Retrieved March, 7, 2020.

- Vinuesa, R., Azizpour, H., Leite, I., Balaam, M., Dignum, V., Domisch, S., .. Nerini, F. F. (2020). The role of artificial intelligence in achieving the Sustainable Development Goals. Nature communications, 11(1), 1-10.

- West, D. M. (2018). The future of work: Robots, Al, and automation: Brookings Institution Press. 
- Willcocks, L. P., \& Lacity, M. (2016). Service automation robots and the future of work: SB Publishing.

- Zufiria, P. J., Pastor-Escuredo, D., Úbeda-Medina, L., Hernandez-Medina, M. A., Barriales-Valbuena, I., Morales, A. J., ... Quinn, J. (2018). Identifying seasonal mobility profiles from anonymized and aggregated mobile phone data. Application in food security. PloS one, 13(4), e0195714. 
REVISTA DIECISIETE
NOTAS Y COLABORACIONES 